REGARDS

SUR LECONOMIE ALLEMANDE

BULLETIN ECONOMIQUE DU CRAC

\section{Regards sur l'économie allemande}

Bulletin économique du CIRAC

$114 \mid 2014$

Varia

\title{
Médias, communication
}

\section{(2) OpenEdition}

1 Journals

Édition électronique

URL : http://journals.openedition.org/rea/4734

DOI : $10.4000 /$ rea.4734

ISSN : 1965-0787

Éditeur

CIRAC

\section{Édition imprimée}

Date de publication : 1 octobre 2014

Pagination : 44

ISSN : 1156-8992

\section{Référence électronique}

"Médias, communication », Regards sur l'économie allemande [En ligne], 114 | octobre 2014, mis en ligne le 01 octobre 2014, consulté le 22 septembre 2020. URL : http://journals.openedition.org/rea/ 4734 ; DOl : https://doi.org/10.4000/rea.4734

Ce document a été généré automatiquement le 22 septembre 2020.

(c) CIRAC 


\section{Médias, communication}

\section{RÉFÉRENCE}

GLÄSER Martin, Medienmanagement, Coll. Vahlens Handbücher der Wirtschafts- und Sozialwissenschaften, Verlag Franz Vahlen, Munich, 3édition, 2014, 1008 p. LOBIGS Frank, NORDHEIM Gerret von (eds), Journalismus ist kein Geschäftsmodell. Aktuelle Studien zur Ökonomie und Nicht-Ökonomie des Journalismus, Coll. Medienökonomie, $\mathrm{n}^{\circ} 5$, Nomos Verlagsgesellschaft, Baden-Baden, 2014, 270 p.

METAG Julia, Politische Kommunikation in lokalen und nationalen Öffentlichkeiten. Ein Vergleich der Rezeptions- und Meinungsbildungsprozesse, Coll. Politische Kommunikation und demokratische Öffentlichkeit, $n^{\circ}$ 9, Nomos Verlagsgesellschaft, Baden-Baden, 2014, $326 \mathrm{p}$.

1 Le management des entreprises des médias est une science à part qui justifie nombre de formations universitaires et requiert des manuels de référence comme celui dont le Prof. Gläser (Medienhochschule Stuttgart) publie là une $3^{\mathrm{e}}$ édition entièrement remaniée. Son approche est holistique, conjuguant dans ses 40 chapitres sciences de la gestion, management, GRH et, bien sûr, théories de la communication, sans oublier le droit spécifique à ce secteur. Dans le domaine de l'économie des médias également, l'ouvrage de LOBIGS et v. NORDHEIM rassemble douze contributions d'enseignantschercheurs (sciences de la communication, économie, formation des journalistes) sur le modèle économique des médias d'information ou plutôt : sur l'articulation de plus en plus difficile entre les lois de l'information et la rentabilité d'une entreprise produisant de l'information. Egalement d'actualité à l'ère d'Internet, la recherche sur la démocratie directe en Allemagne et ailleurs, objet de la thèse de doctorat de METAG en sociologies et sciences de l'éducation (Université de Münster). (Isabelle Bourgeois) 